\title{
A comparison of consumer sensory acceptance and value of domestic beef steaks and steaks from a branded, Argentine beef program ${ }^{1.2}$
}

\author{
K. M. Killinger*, C. R. Calkins ${ }^{* 3}$, W. J. Umberger $\dagger$, D. M. Feuz $\dagger$, and K. M. Eskridge \\ *Animal Science Department, $\dagger$ Department of Agriculture Economics, and \\ $\ddagger$ Department of Biometry, University of Nebraska, Lincoln 68583
}

\begin{abstract}
To determine consumer sensory acceptance and value of branded, Argentine (grass-finished, aged $30+d$ ) and domestic (U.S. grain-finished beef, aged 9 d) strip loins were paired based on similar WarnerBratzler shear force values $(P=0.34)$ and similar marbling levels $(P=0.82)$. Consumers in Chicago, IL, and San Francisco, CA ( $\mathrm{n}=124$ per city), evaluated one pair of Argentine and domestic steaks, and had the opportunity to participate in a silent, sealed-bid auction to purchase steaks matching the taste panel samples. Consumers were categorized into three groups based on overall acceptability ratings: 1) those who found Argentine steaks more acceptable, 2) those who found domestic steaks more acceptable, and 3) those who were indifferent. Consumers rated domestic steaks higher $(P<0.05)$ in juiciness, tenderness, flavor, and overall acceptability. Consumers in both Chicago and San
\end{abstract}

Francisco were willing to pay more $(P<0.05)$ for domestic steaks ( $\$ 0.86$ and $\$ 0.52$ per $0.45 \mathrm{~kg}$, respectively). In both cities, consumers who found Argentine samples more acceptable were willing to pay more $(P<0.05)$ for Argentine steaks $(\$ 0.74$ per $0.45 \mathrm{~kg}$ in Chicago and $\$ 1.82$ per $0.45 \mathrm{~kg}$ in San Francisco), and consumers who found domestic samples more acceptable were willing to pay more $(P<0.05)$ for domestic steaks $(\$ 1.66$ per 0.45 $\mathrm{kg}$ in Chicago and $\$ 1.34$ per $0.45 \mathrm{~kg}$ in San Francisco). Consumers who were indifferent were willing to pay similar $(P=0.99)$ amounts for Argentine and domestic steaks. Although some consumers found Argentine beef more acceptable than domestic beef (19.7 and 16.5\% in Chicago and San Francisco, respectively) and were willing to pay more for it, most consumers found domestic beef to be more acceptable $59.0 \%$ in Chicago and $61.5 \%$ in San Francisco) and were willing to pay more to obtain a more acceptable product.

Key Words: Beef Quality, Consumer Panels, Consumer Prices

(C2004 American Society of Animal Science. All rights reserved.

J. Anim. Sci. 2004. 82:3302-3307

\section{Introduction}

Beef production in different countries can vary in many aspects, including cattle genetics, use of implants, feeding practices, quality of feedstuffs, and meat processing procedures. These factors can potentially create fresh beef products that are quite different, depending on the country of origin. Argentine beef is typically from grass-finished cattle and has been characterized as having a unique flavor. Beef production in the United States, however, typically involves feeding high-

\footnotetext{
${ }^{1}$ Published as Paper No. 14010, Journal Series, Nebraska Agric. Res. Div., Univ. of Nebraska, Lincoln 68583-0908.

${ }^{2}$ This project was funded in part by beef producers through their $\$ 1$-per-animal check-off and was produced for the Cattlemen's Beef Board and state beef councils by the National Cattlemen's Beef Association.

${ }^{3}$ Correspondence: A213 Animal Science (phone: 402-472-6314; fax: 402-472-6362; e-mail: ccalkins1@unl.edu).

Received February 28, 2003.

Accepted July 21, 2004.
}

grain diets before slaughter. Certainly, studies have noted grain-finished beef rated higher in flavor desirability (Wanderstock and Miller, 1948; Hedrick et al., 1983) and overall acceptability (Aalhus et al., 1992) compared with grass-finished beef. However, differences in grass- and grain-finished beef cannot explain all the differences between Argentine and domestic beef. Differences also exist in the use of growth-promoting hormones and extent of cooler aging. Therefore, the objective of the study was to determine consumer acceptance and value of branded, Argentine beef and domestic U.S. beef when tenderness levels and marbling levels were similar between products.

\section{Materials and Methods}

Taste panel studies were conducted in Chicago, IL, and San Francisco, CA. This particular study was conducted as a portion of a larger project involving visual evaluation of beef, as well as sensory evaluation of several beef samples. 


\section{Collection of Strip Loins}

Two hundred twenty-three domestic beef strip loins of two marbling scores (Small and Slight) were purchased and delivered to the Loeffel Meat Laboratory at the University of Nebraska, Lincoln. Branded, Argentine strip loins ( $\mathrm{n}=49$ ) were purchased from an Argentine supplier and also delivered to the Loeffel Meat Laboratory. All domestic strip loins were aged for $7 \mathrm{~d}$ at $3^{\circ} \mathrm{C}$ (9 d total aging time) and subsequently frozen at $-35.5^{\circ} \mathrm{C}$ until further fabrication. Argentine strip loins were frozen soon after arrival. Aging of Argentine beef was not under experimental control, and the exact aging period was unknown; however, information provided by the Argentine supplier indicated that the beef was aged for at least $30 \mathrm{~d}$, which assured that the Argentine beef was aged for a longer period than the domestic beef. The Argentine product was merchandised as natural beef (raised without use of hormones implants), and cattle were grass-finished. No information was known about the age of the animals at slaughter. Strip loins were tempered in a $3^{\circ} \mathrm{C}$ cooler for a period of no more than $24 \mathrm{~h}$ before being cut into 2.54-cm-thick steaks on a band-saw (Biro Manufacturing Co., Marblehead, $\mathrm{OH}$ ). Steaks were trimmed to approximately $0.3 \mathrm{~cm}$ of external fat, individually wrapped in butcher paper, labeled, and returned to the freezer.

\section{Warner-Bratzler Shear Force Determination}

The most anterior steak (Steak 1) was collected from each strip loin, and thawed at $4^{\circ} \mathrm{C}$ for approximately $24 \mathrm{~h}$. Marbling scores were determined for Argentine steaks by two trained individuals (scores were averaged), whereas marbling scores for domestic steaks had been assigned previously by a USDA grader. Steaks were cooked on Open Hearth Broilers (Farberware, Bronx, NY), and temperature was monitored intermittently with a thermocouple thermometer (model 450ATT; Omega Engineering, Inc., Stamford, CT). Steaks were turned at $35^{\circ} \mathrm{C}$, and cooked to an internal end point temperature of $70^{\circ} \mathrm{C}$. Steaks were cooled for approximately $2 \mathrm{~h}$ at $18^{\circ} \mathrm{C}$, after which eight (or more) 1.27 -cm-diameter cores were removed from the steaks parallel to the longitudinal orientation of the muscle fibers using a mechanical coring device (model 11-950; Delta, Pittsburgh, PA). Cores were then sheared perpendicular to the longitudinal orientation of the muscle fibers with a Warner-Bratzler shear head attached to an Instron Universal Testing Machine (model 55R1123; Instron Corp., Canton, MA) equipped with a $500-\mathrm{kg}$ load cell and a crosshead speed setting of $250 \mathrm{~mm} / \mathrm{min}$. Peak shear force data were collected and recorded using accompanying Merlin software (Instron Corp.).

\section{Chemical Analyses}

The second-most anterior steak (Steak 2) was reserved for chemical analysis. Steaks were thawed, trimmed of external fat, and cut into small pieces. Then, samples were pulverized in liquid $\mathrm{N}$ using a Waring blender (Dynamics Corp. of America, New Hartford, CT). Duplicate samples were analyzed for moisture and ash using a thermogravimetric analyzer (Leco Corp., St. Joseph, MI). For ether-extracted lipid content, duplicate samples were distilled in anhydrous ether for 72 $\mathrm{h}$ according to the Soxhlet method (AOAC, 1990).

\section{Pairing of Strip Loins}

Branded, Argentine strip loins comparable to the Slight degree of marbling were paired with domestic, U.S. Select strip loins based on similar $(<0.15 \mathrm{~kg})$ Warner-Bratzler shear force values. For taste panel evaluation, consumers tasted a warm-up sample, as recommended by the AMSA (1978) guidelines, selected from the low U.S. Choice strip loin steaks.

Selected strip loins were assigned three-digit random codes. Matched pairs of strip loins were then assigned randomly to evaluation sessions; each session had one matched pair of domestic and branded, Argentine beef. Steaks 3 through 5 (anterior to posterior) were designated for taste panel samples, whereas steaks 6 through 11 were designated for sale during experimental auctions. Frozen steaks used in the auctions were packaged as pairs in plastic bags to achieve packages of frozen steaks that would weigh approximately 0.45 $\mathrm{kg}$ total when thawed. Steaks were shipped frozen to the host facilities, and held in freezers at the facilities $\left(-26.0^{\circ} \mathrm{C}\right.$ in Chicago and $-12.2^{\circ} \mathrm{C}$ in San Francisco) for less than $1 \mathrm{wk}$ before the evaluation sessions.

\section{Screening of Panelists}

Consumers in both cities were screened over the telephone by employees of the host facilities to determine whether they qualified for the study. To qualify, consumers had to be the primary grocery shopper in the household or share shopping duties equally with another member of the household. In addition, consumers had to be between the ages of 19 to $59 \mathrm{yr}$, and had to be willing to consume beef. Consumers and their immediate families could not be employed in any portion of the meat animal industry, market research, advertising, or news reporting. In each city, qualified consumers were scheduled for evaluation sessions that were held for $3 \mathrm{~d}$ with four sessions per day, with a target of 12 consumers per session.

In each city, 124 consumers participated in the study. Participation in each evaluation session ranged from six to 12 consumers. The majority of consumers were age $35 \mathrm{yr}$ or older, and most consumed beef in their homes three to four times each week. In Chicago, 82.3\% of consumers were female, and $97.5 \%$ were Caucasian, whereas in San Francisco, $77.4 \%$ were female, and $81.9 \%$ were Caucasian.

\section{Collection of Demographic Information}

Consumers who qualified and agreed to participate were mailed a consent form and a survey that ascer- 
tained information on their eating preferences, meat purchasing behaviors, and other demographic characteristics. Consumers were asked to bring these forms with them to the evaluation sessions. On arrival at the facility, consumers were paid in cash for their participation (\$25 and \$35 in Chicago and San Francisco, respectively), which was comparable to other test-marketing facilities in the respective cities. Panelist identification codes were assigned to maintain anonymity throughout the procedures. Consumers also completed a meat knowledge survey. After completing a meat knowledge survey, consumers were asked to visually evaluate steaks in a retail display case (Killinger et al., 2004).

\section{Taste Panel Sample Preparation}

While the consumers were arriving, taste panel samples were cooked in the test kitchen of each facility. Steaks 3,4 , and 5 were prepared for sensory evaluation. These frozen steaks were thawed in a walk-in cooler or refrigerator $\left(1^{\circ} \mathrm{C}\right)$ for approximately $24 \mathrm{~h}$. Three Open Hearth Broilers (Farberware, Bronx, NY) were used to cook steaks according to AMSA (1978) guidelines. Steaks were cooked to an internal temperature of $70^{\circ} \mathrm{C}$, wrapped in aluminum foil with an identification tag, and held in a steam-jacketed table (Hot Food Boxes, Inc., Chicago, IL) or waterless food warmer (Duke Manufacturing, St. Louis, MO) until immediately before serving. Steaks were then cut into $1-\times 2-\times 1$-cm pieces for sensory evaluations, and a single sample served warm to each consumer.

\section{Explanation of Auction Procedures}

To maintain consistency throughout the evaluation sessions, a moderator read a written explanation of the experimental auction procedures to the consumers. The written explanation by Menkhaus et al. (1990) was used as a model when developing the explanation. In brief, the explanation informed the consumers that they would have the opportunity to purchase steaks from the same strip loins as the taste panel samples by submitting bids in a silent, sealed-bid auction; however, they were not required to participate in the auctions. After the explanation, three practice auctions were conducted as described by Killinger et al. (2004).

\section{Taste Panel Evaluations and Purchase Auctions}

Consumers were reminded that the auctions following the three practice auctions would be binding, and a winning bid would require the consumer to pay the market price determined in that auction. They were reminded that they would be bidding for a 0.45 -kg package of frozen steak (two steaks per package) from the same strip loin as the taste panel samples. Consumers rated samples for juiciness, tenderness, flavor, and overall acceptability using an eight-point scale $(1=$ extremely dry, tough, and undesirable to $8=$ extremely juicy, tender, and desirable). Consumers separately evaluated each sample in a matched pair, and after evaluating both samples, consumers were given two auction bid sheets (one for each sample they had evaluated). Consumers submitted their bids and recorded them on their record sheets. Servers collected the bid sheets and determined the winning bids and market price. One comparison of domestic and branded, Argentine beef was made. Servers kept records of the consumers' winning bids and the market prices.

\section{Reconciliation of Accounts and Steak Distribution}

After completing the last auction, consumers, the moderator, and servers gathered in a conference room. If consumers had not purchased any steaks and their records agreed with the servers' records, they were free to leave. A server then reconciled their records with each remaining consumer's records, and the consumers bought the steaks that they had won. Frozen steaks were distributed once records were reconciled. When the Argentine steaks were thawed for Warner-Bratzler shear determination, it was noticed that the meat had an odor that was different than the odor of the grainfinished, domestic beef. Research has noted that beef aged in a vacuum-package for $20 \mathrm{~d}$ has increased offodor compared with shorter aging times (Jennings et al., 1978; Seideman et al., 1982). It was feared that consumers might misinterpret the odor of the Argentine beef as a spoiled odor; therefore, it was decided that Argentine beef would not be distributed to consumers. Instead, consumers winning the auction for Argentine steaks could, but were not required to, purchase a package of substitute steaks.

\section{Statistical Analyses}

All 248 consumers were included in the sensory evaluation portion of the analysis. Consumers who consistently submitted bids of $\$ 0.00$ were, however, removed from the analysis of auction bids, as these consumers were unwilling to provide information on their value for the products. Therefore, 226 consumers were included in the analysis of auction bids. For the taste panel and overall auction data, the experimental design was a randomized complete block design with evaluation session within city, panelist within city, and session as the blocking factors. In the ANOVA, main effects included in the model were city $(\mathbf{C})$, evaluation session $(\mathbf{S})$, panelist $(\mathbf{P})$, and product (B; domestic or Argentine), as well as $\mathrm{P}$ within $\mathrm{S} \times \mathrm{C}, \mathrm{B}$ within $\mathrm{C}, \mathrm{B} \times \mathrm{S}$ within $\mathrm{C}$, and $\mathrm{B} \times \mathrm{P}$ within $\mathrm{S} \times \mathrm{C}$. All factors were considered fixed, except panelist and evaluation session, which were considered as random effects. Because consumers were not compensated with the same amount in both cities, price data between cities were not compared.

Based on overall acceptability ratings, consumers were categorized into three groups: 1) those who found domestic steaks more acceptable, 2) those who found Argentine steaks more acceptable, and 3) those who 
Table 1. Palatability ratings for domestic and Argentine beef

\begin{tabular}{lccc}
\hline \hline Attribute $^{\mathrm{a}}$ & Domestic & Argentine & SE \\
\hline Flavor & $5.9^{\mathrm{b}}$ & $4.6^{\mathrm{c}}$ & 0.15 \\
Juiciness & $5.0^{\mathrm{b}}$ & $4.5^{\mathrm{c}}$ & 0.16 \\
Tenderness & $5.8^{\mathrm{b}}$ & $5.1^{\mathrm{c}}$ & 0.14 \\
Overall acceptability & $5.7^{\mathrm{b}}$ & $4.6^{\mathrm{c}}$ & 0.14 \\
\hline
\end{tabular}

${ }^{\mathrm{a}} 1$ = extremely undesirable, dry, tough, and undesirable to $8=$ extremely desirable, juicy, tender, and desirable.

${ }^{b, c}$ Within a row, means without a common superscript letter differ, $P<0.05$.

were indifferent. Using these acceptability groups, auction data were analyzed as a split-plot design with acceptability group as the whole plot and product (domestic or Argentine) as the subplot. Factors included in the model were C, S, P, acceptability group $(\mathbf{G})$, and B (domestic and branded, Argentine), as well as $\mathrm{S}$ within $\mathrm{C}, \mathrm{G}, \mathrm{G} \times \mathrm{S}$ within $\mathrm{C}, \mathrm{P}$ within $\mathrm{G} \times \mathrm{S} \times \mathrm{C}$ (whole plot error term), $\mathrm{B} \times \mathrm{C}, \mathrm{B} \times \mathrm{S}$ within $\mathrm{C}, \mathrm{B} \times \mathrm{P}$ within $\mathrm{S} \times \mathrm{G}$, $\mathrm{B} \times \mathrm{G}, \mathrm{B} \times \mathrm{G} \times \mathrm{C}$, and $\mathrm{B} \times \mathrm{G} \times \mathrm{S}$ within $\mathrm{C}$. With the exception of panelist and evaluation session (random effects), all factors were considered as fixed effects.

Differences in Warner-Bratzler shear force, marbling score, and chemical analysis data between paired domestic and branded, Argentine strip loins were analyzed using the paired $t$-test statement in the means procedure of SAS (SAS Inst., Inc., Cary, NC). Absolute means and differences were reported for this data.

The mixed models procedure of SAS was used for ANOVA of all data, and least squares means were separated using Fisher's LSD. All means were reported as least square means, except as noted previously for chemical analysis data, Warner-Bratzler shear force data, and marbling score data. Partial correlations between sensory variables, removing the effect of treatment, were determined using the GLM procedure of SAS. Responses on surveys were analyzed for differences between cities and between acceptability groups using the $\chi^{2}$ test.

\section{Results and Discussion}

Consumers rated domestic steaks higher $(P<0.05)$ in flavor, juiciness, tenderness, and overall acceptability (Table 1). The domestic and Argentine strip loins were paired based on similar $(P=0.34)$ Warner-Bratzler shear force values, with an average difference in shear force value of $0.01 \pm 0.01 \mathrm{~kg}$; however, consumers still rated domestic steaks higher in tenderness. Crouse et al. (1978) found that ratings for overall acceptability, juiciness, and flavor were less correlated with WarnerBratzler shear value than with tenderness ratings, indicating that subjective tenderness ratings were influenced by other characteristics. Harrison et al. (1978) also found that although shear force value did not differ between feeding regimens, trained panelists found grass-fed beef to be less tender than grain-fed beef.
Table 2. Partial correlation coefficients among palatability ratings and auction bids

\begin{tabular}{lcccc}
\hline \hline Trait & Flavor & Juiciness & Tenderness & $\begin{array}{c}\text { Overall }_{\text {acceptability }} \\
\text { a }\end{array}$ \\
\hline $\begin{array}{l}\text { Overall }_{\text {acceptability }}^{\mathrm{a}} \\
\text { Auction bid }\end{array}$ & $0.86^{\mathrm{a}}$ & $0.75^{*}$ & $0.74^{*}$ & - \\
\hline
\end{tabular}

${ }^{\mathrm{a}} 1=$ extremely undesirable to $8=$ extremely desirable. $* P<0.01$.

Consumers in this study rated domestic steaks more than one taste panel score higher in flavor and overall acceptability, as well as half of one score higher in juiciness. It is plausible that the stark differences in these attributes influenced the consumers' ratings for tenderness.

In other studies, consumers have found grain-finished beef to be juicier than grass-finished beef (Aalhus et al., 1992). Additionally, studies have noted increased flavor desirability (Wanderstock and Miller, 1948; Hedrick et al., 1983) and overall acceptability (Aalhus et al., 1992) of grain-finished beef compared with grassfinished beef. In this study, Argentine and domestic beef were matched for similar Warner-Bratzler shear force values $(P=0.34)$ and marbling level $(P=0.82)$. Chemical analysis data confirmed that paired samples were similar $(P=0.39)$ in fat content (5.46 and 5.21\% fat for Argentine and domestic steaks, respectively). Argentine and domestic steaks were also similar $(P=$ 0.66) in moisture content, but domestic steaks were slightly higher $(P<0.10)$ in ash content. Therefore, in this study, differences observed in palatability between domestic and Argentine steaks were likely attributable to differences in feeding practices and aging time.

Consumers in this study overwhelmingly found domestic steaks to be juicier, more tender, and more desirable in flavor and overall acceptability. Typically, longer wet-aging periods have not been observed to affect flavor and juiciness to a great extent (Seideman et al., 1982; Jones et al., 1991; Aalhus et al., 1992). Nonetheless, it is not possible to exclude aging as a factor that contributed to palatability differences in this study, especially when the extended aging period of 30 $\mathrm{d}$ or more is considered. Flavor ratings were most highly correlated with overall acceptability $r=0.86$ ), followed by juiciness and tenderness (Table 2 ).

Both consumers in Chicago and San Francisco were willing to pay more $(P<0.05)$ for domestic beef (Table 3 ). Obviously, the bids submitted typically did not reflect retail value for fresh beef steaks. The tendency for consumers to underbid in a second-price auction was observed by Coursey et al. (1984); however, the amount by which consumers underbid was consistent. Thus, the bids reflected the relative rank by the participants. Menkhaus et al. (1992) suggested that, when comparing two products, the differential between the bids submitted for the products represents a true difference in value 
Table 3. The price $(\$ / 0.45 \mathrm{~kg})$ consumers were willing to pay $( \pm \mathrm{SE})$ for Argentine and domestic strip steaks based on auction bids

\begin{tabular}{lcc}
\hline \hline Product & Chicago & San Francisco \\
\hline Domestic & $\$ 2.66 \pm 0.19^{\mathrm{a}}$ & $\$ 2.64 \pm 0.19^{\mathrm{a}}$ \\
Argentine & $\$ 1.80 \pm 0.19^{\mathrm{b}}$ & $\$ 2.12 \pm 0.19^{\mathrm{b}}$ \\
Price differential & $\$ 0.86 \pm 0.22$ & $\$ 0.52 \pm 0.23$ \\
\hline
\end{tabular}

${ }^{\mathrm{a}, \mathrm{b}}$ Within a column, means without a common superscript letter differ, $P<0.05$.

(more than the absolute bids themselves). Therefore, in this study, results from the auction data indicated that consumers in Chicago were willing to pay $\$ 0.86$ / $0.45 \mathrm{~kg}$ more $(P<0.05)$, whereas consumers in San Francisco were willing to pay $\$ 0.52 / 0.45 \mathrm{~kg}$ more $(P<$ $0.05)$ for domestic steaks. Overall acceptability ratings were most highly correlated with auction bids (Table 2 ). Consumers conveyed that domestic beef was more acceptable in palatability, and they were willing to pay more for a more acceptable product.

To more closely examine the auction bids submitted by consumers, overall acceptability ratings were used to categorize the consumers. Consumers were divided into three groups based on overall acceptability ratings: 1) those who rated the domestic steaks higher in overall acceptability, 2) those who rated the Argentine steaks higher in overall acceptability, and 3) those who rated samples the same. Using these groupings, an analysis of the auction bids was performed (Table 4). It should be noted that in this study, one pair of samples was evaluated, so it was likely that consumers would either find Argentine or domestic beef more acceptable.

In Chicago, $19.7 \%$ of consumers found Argentine beef to be more acceptable, $59.0 \%$ found domestic beef to be more acceptable, and $21.3 \%$ were indifferent. The consumers who found Argentine beef more acceptable were willing to pay $\$ 0.74 / 0.45 \mathrm{~kg}$ more $(P<0.01)$ for the sample that they found more acceptable. Consumers who found domestic beef more acceptable were willing to pay $\$ 1.66 / 0.45 \mathrm{~kg}$ more for domestic steaks. If consumers were indifferent, then they were willing to pay similar $(P=0.99)$ amounts for Argentine and domestic steaks.

In San Francisco, 16.5\% of consumers found Argentine samples more acceptable based on overall acceptability ratings, $61.5 \%$ found domestic steaks more acceptable, and $22.0 \%$ of consumers were indifferent. Consumers who found Argentine beef more acceptable were willing to pay $\$ 1.82 / 0.45 \mathrm{~kg}$ more $(P<0.01)$ for Argentine steaks, and consumers who found domestic steaks more acceptable were willing to pay $\$ 1.34 / 0.45 \mathrm{~kg}$ more $(P<0.01)$ for domestic steaks. Consumers who were indifferent were willing to pay similar $(P=0.66)$ amounts for Argentine and domestic steaks.

It is interesting that the consumers in Chicago, who found domestic steaks more acceptable, were willing to pay more than those who found Argentine steaks more acceptable ( $\$ 1.66$ vs. $\$ 0.74 / 0.45 \mathrm{~kg}$, respectively). However, in San Francisco, consumers who found Argentine steaks more acceptable were willing to pay more than consumers who found domestic steaks more acceptable ( $\$ 1.82$ vs. $\$ 1.34 / 0.45 \mathrm{~kg}$, respectively).

In a further analysis of this study, some demographic characteristics were linked with acceptability groups (Umberger, 2001). Females tended $(P=0.10)$ to be less likely than males to find domestic beef more acceptable. Consumers who ate beef more often and those who typically purchased U.S. Choice beef were more likely to find domestic beef more acceptable, whereas nonCaucasian consumers were more likely to find Argentine beef more acceptable.

There were also differences noted between acceptability groups in regard to meat knowledge. With regard to the overall meat knowledge score, consumers who found domestic beef more acceptable tended to score higher $(P<0.10)$ on the quiz than consumers who found Argentine beef more acceptable or those who were indifferent. This trend was also supported specifically by three questions on the meat knowledge survey. The percentage of consumers who correctly answered that beef was not a good source of Vitamin C was different $(P<0.01)$, with $89.6,78.1$, and $68.8 \%$ of consumers who preferred domestic beef, preferred Argentine beef, or were indifferent answering the question correctly, re-

Table 4. The price $(\$ / 0.45 \mathrm{~kg})$ consumers were willing to pay, based on auction bids, for Argentine and domestic strip loin steaks stratified across consumers groups based on overall acceptability ratings in Chicago, IL, and San Francisco, $\mathrm{CA}^{\mathrm{a}}$

\begin{tabular}{lccccccc}
\hline \hline & \multicolumn{3}{c}{ Chicago, IL } & & \multicolumn{3}{c}{ San Francisco, CA } \\
\cline { 2 - 3 } \cline { 7 - 8 } Product & $\begin{array}{c}\text { Liked } \\
\text { domestic }\end{array}$ & $\begin{array}{c}\text { Liked } \\
\text { Argentine }\end{array}$ & Indifferent & & $\begin{array}{c}\text { Liked } \\
\text { domestic }\end{array}$ & $\begin{array}{c}\text { Liked } \\
\text { Argentine }\end{array}$ & Indifferent \\
\hline No. of consumers & 69 & 23 & 25 & & 67 & 18 & 24 \\
Domestic & $\$ 2.92^{\mathrm{b}}$ & $\$ 2.28^{\mathrm{c}}$ & $\$ 2.26$ & & $\$ 2.87^{\mathrm{b}}$ & $\$ 1.23^{\mathrm{c}}$ & $\$ 3.13$ \\
Argentine & $\$ 1.26^{\mathrm{c}}$ & $\$ 3.02^{\mathrm{b}}$ & $\$ 2.26$ & & $\$ 1.53^{\mathrm{c}}$ & $\$ 3.05^{\mathrm{b}}$ & $\$ 3.00$ \\
SE & 0.20 & 0.32 & 0.30 & & 0.21 & 0.36 & 0.31 \\
Differential $( \pm \mathrm{SE})$ & $\$ 1.66 \pm 0.18$ & $\$ 0.74 \pm 0.29$ & $\$ 0.00 \pm 0.28$ & & $\$ 1.34 \pm 0.19$ & $\$ 1.82 \pm 0.33$ & $\$ 0.13 \pm 0.28$ \\
\hline
\end{tabular}

${ }^{\mathrm{a}} 1$ = extremely undesirable to 8 = extremely desirable.

${ }^{\mathrm{b}, \mathrm{c}}$ Within a column, means without a common superscript letter $\operatorname{differ}, P<0.05$. 
spectively. A higher $(P<0.05)$ percentage $(71.3 \%)$ of consumers who liked domestic beef correctly identified an ingredient that would not tenderize beef in a marinade compared with the percentage of correct responses by those who preferred Argentine beef (53.7\%) and those who were indifferent (56.5\%). Additionally, a higher $(P<0.05)$ percentage $(80.9 \%)$ of consumers who found domestic beef more acceptable correctly identified a retail cut that would be most appropriately prepared by broiling compared with the percentage of correct responses by those who found Argentine beef more acceptable $(65.9 \%)$ and those who were indifferent (66.7\%). Differences $(P<0.10)$ were also detected between acceptability groups and economic category. The highest percentage $(19.6 \%)$ of consumers who found domestic beef more acceptable had a yearly household income of $\$ 100,000$ or more, and the highest percentage (22.5\%) of consumers who found Argentine beef more acceptable had a yearly household income of $\$ 50,000$ to $\$ 59,999$. The highest percentage (21.3\%) of consumers who were indifferent had a yearly household income of $\$ 60,000$ to $\$ 69,999$.

\section{Implications}

When differences in tenderness and marbling level were minimized between domestic, grain-fed (aged $9 \mathrm{~d}$ ) and branded, grass-fed, Argentine (aged 30+ d) beef, consumers found domestic beef to be more palatable. Although a niche market may exist for branded, Argentine beef, most consumers found domestic beef more acceptable and were willing to pay more for domestic steaks.

\section{Literature Cited}

Aalhus, J. L., S. D. M. Jones, A. K. W. Tong, L. E. Jeremiah, W. M. Robertson, and L. L. Gibson. 1992. The combined effect of time on feed, electrical stimulation and aging on beef quality. Can. J. Anim. Sci. 72:525-535.

AMSA. 1978. Guidelines for Cookery and Sensory Evaluation of Meat. Am. Meat Sci. Assoc., Kansas City, MO.
AOAC. 1990. Offical Methods of Analysis. 15th ed. Assoc. Off. Anal. Chem., Washington. DC.

Coppinger, V. M., V. L. Smith, and J. A. Titus. 1980. Incentives and behavior in English, Dutch and sealed-bid auctions. Econ. Inq. 18:1-22.

Coursey, D. L., and V. L. Smith. 1984. Experimental tests of an allocation mechanism for private, public or externality goods. Scand. J. Econ. 86:468-484.

Crouse, J. D., G. M. Smith, and R. W. Mandigo. 1978. Relationship of selected beef carcass traits with meat palatability. J. Food Sci. 43:152-157.

Harrison, A. R., M. E. Smith, D. M. Allen, M. C. Hunt, C. L. Kastner, and D. H. Kropf. 1978. Nutritional regime effects on quality and yield characteristics of beef. J. Anim. Sci. 47:383-388.

Hedrick, H. B., J. A. Paterson, A. G. Matches, J. D. Thomas, R. E. Morrow, W. C. Stringer, and R. J. Lipsey. 1983. Carcass and palatability characteristics of beef produced on pasture, corn silage and corn grain. J. Anim. Sci. 57:791-801.

Jennings, T. G., B. W. Berry, and A. L. Joseph. 1978. Influence of fat thickness, marbling and length of aging on beef palatability and shelf-life characteristics. J. Anim. Sci. 46:658-665.

Jones, S. D. M., L. E. Jeremiah, A. K. W. Tong, S. Lutz, and W. M. Robertson. 1991. The effects of marbling level, electrical stimulation, and post-mortem aging on the cooking and palatability properties of beef rib-eye steaks. Can J. Anim. Sci. 71:1037-1043.

Killinger, K. M., C. R. Calkins, W. J. Umberger, D. M. Feuz, and K. M. Eskridge. 2004. Consumer visual preference and value for beef steaks differing in marbling level and color. J. Anim. Sci. 82:3288-3293.

Menkhaus, D. J., G. W. Borden, G. D. Whipple, E. Hoffman, and R. A. Field. 1992. An empirical application of laboratory experimental auctions in marketing research. Agric. Res. Econ. 17:44-55.

Menkhaus, D. J., R. A. Field, and G. D. Whipple. 1990. Economic value of case ready meats as determined by the consumer: Methods. Report to the Beef Industry Council of the National Livestock and Meat Board. Chicago, IL.

Seideman, S. C., J. D. Crouse, and H. R. Cross. 1982. Effect of feeding regimen and vacuum-packaged storage on sensory and physical properties of beef steaks. J. Food Prot. 45:1227-1231.

Umberger, W. J. 2001. Consumer willingness-to-pay for flavor in beef steaks: An experimental economics approach. Ph.D. Diss., Univ. of Nebraska, Lincoln.

Vickery, W. 1961. Counterspeculation, auctions and competitive sealed tenders. J. Finan. 16:8-37.

Wanderstock, J. J., and J. I. Miller. 1948. Quality and palatability of beef as affected by method of feeding and carcass grade. Food Res. 13:291-303. 